\title{
“Não, Tempo, não te gabarás de que eu mudo!” Evidências da Dimensão Temporal na Aprendizagem de Praticantes da Estratégia no Setor Público
}

\section{"No, Time, thou shalt not boast that I do change!" Evidences of Temporal Dimension in the Learning of Strategy Practitioners in the Public Sector}

\author{
José Alberto de Siqueira Brandão \\ Secretaria de Planejamento e Gestão do Estado de Pernambuco - SEPLAG/PE - Brasil \\ albertobrandao@gmail.com \\ ORCID: 0000-0003-2291-6522
}

Eduardo de Aquino Lucena

Universidade Federal de Pernambuco - UFPE - Brasil

eaqlucena@yahoo.com.br

ORCID: 0000-0001-8441-7337

Submetido em 25/03/2018; Aprovado em 19/09/2018

\begin{abstract}
Resumo
A discussão sobre como a aprendizagem acontece nas organizações se intensificou nas últimas décadas. Talvez esse debate seja mais intenso no setor público, dadas as transformações exigidas pela sociedade. Este artigo tem como objetivo discutir a dimensão temporal da aprendizagem social em uma política pública educacional. Para tanto, optou-se por realizar um estudo de caso qualitativo, desenvolvido em conformidade com as técnicas da teoria fundamentada propostas por Charmaz (2014), versando sobre a experiência relacionada ao "Pacto pela Educação em Pernambuco", conhecido como PEP. A interpretação dos achados indica a existência de relações entre aprendizagem em diferentes níveis gerenciais e a dimensão temporal no PEP.
\end{abstract}

Palavras-chave: dimensão temporal; aprendizagem social; praticantes da estratégia; setor público.

\section{Abstract}

The discussion on how learning happens in organizations has intensified in recent decades. Perhaps this debate is most intense in the public sector, given the transformations called for by society. This paper aims to discuss the temporal dimension of social learning in a public educational policy in Pernambuco. To this end, we chose to conduct a qualitative case study, in accordance with the techniques of the grounded theory proposed by Charmaz (2014), about the experience related to the "Pact for Education in Pernambuco", known as PEP. The interpretation of the findings indicates the existence of relationships between learning at different managerial levels and the temporal dimension in PEP.

Keywords: temporal dimension; social learning; strategy practitioners; public sector.

\section{Introdução}

O verso introdutório do soneto 123 atribuído a William Shakespeare que compõe o título do presente artigo introduz a discussão sobre o papel exercido pelo tempo em relação às mudanças vivenciadas pelos seres humanos. Atualmente as mudanças são continuamente requeridas de indivíduos e organizações em face da inserção de novas tecnologias, destacando-se a importância de se compreender a importância da dimensão temporal para a aprendizagem.

Um dos segmentos que vem vivenciando com maior intensidade essas mudanças é o setor público. A administração pública tem sido dominada por quase um século por ideias decorrentes da tradição burocrática. Nas últimas décadas foram desenvolvidas diferentes perspectivas, dando maior destaque à escola denominada New Public Management - NPM, que enfatiza o processo de mensuração e avaliação dos resultados, com foco no desempenho na prestação de serviços públicos (Pollitt, 2007). Recentemente a perspectiva da New Public Governance - NPG tornou-se evidente, reconhecendo a natureza plural do Estado e a complexidade do desenvolvimento e implantação de políticas públicas, influenciadas por condições contextuais e por inter-relações organizacionais (Osborne, 2006). Deste 
modo, o setor público se configura com elevado potencial a ser explorado no campo dos estudos sobre aprendizagem de seus atores em diferentes esferas governamentais.

Este artigo tem como objetivo discutir a dimensão temporal da aprendizagem social em uma política educacional pública, vivenciada no âmbito do Estado de Pernambuco. Para isso, a aprendizagem é concebida "como participação em processos sociais enfatizando questões de conhecimento e questões de ser e tornar-se" (Brandi \& Elkjaer, 2011, p. 24). A aprendizagem acontece através de processos transacionais entre os indivíduos socializados e seu contexto social interpretado em uma relação entre "sujeito" e "mundos".

Com este intuito, a política pública denominada "Pacto pela Educação em Pernambuco" - PEP foi escolhido como um estudo de caso qualitativo. Esta política tem como linhas de atuação a transparência das informações, o estabelecimento de metas e o acompanhamento de resultados (Alessandro, Lafuente, \& Shostak, 2014), possibilitando o reconhecimento da necessidade de aprendizagem oriunda da introdução de novas práticas de gestão no âmbito da Administração Pública. A aprendizagem observada nos praticantes da estratégia desta política despertou o interesse dos pesquisadores em estudar este fenômeno.

\section{Referencial Teórico}

Para a construção desta seção foi desenvolvido um processo de levantamento prévio em fontes bibliográficas, processo este que foi continuado conforme ocorriam contribuições oriundas do processo de coleta de dados. Inicialmente é apresentada a perspectiva da aprendizagem social, corrente de pensamento que orientou a condução do estudo. Em seguida, introduz-se o debate acerca do tempo enquanto dimensão constitutiva da aprendizagem. No fechamento da seção são discutidos os principais conceitos para a compreensão do fenômeno da aprendizagem de praticantes da estratégia no âmbito das organizações atuantes no setor público.

\subsection{A Perspectiva da Aprendizagem Social}

Uma tentativa de entender o fenômeno da aprendizagem proporcionou a construção de um mapeamento embasado nas dicotomias entre teoria-prática e processo-conteúdo, com a definição do campo em quatro termos: aprendizagem organizacional, organizações que aprendem, conhecimento organizacional e gestão do conhecimento (Easterby-Smith \& Lyles, 2011). Em outra vertente, são explicitadas duas correntes principais, sendo a primeira vinculada à epistemologia da posse, com caráter mais individual-cognitivista, e a segunda ligada à epistemologia da participação em comunidades de prática, que enfatiza uma visão socioprática (Dos-Santos, Brito-de-Jesus, Souza-Silva, \& Rivera-Castro, 2015).

A construção de uma visão conciliadora foi objeto de estudiosos (Sfard, 1998; Elkjaer, 2004), culminando com o desenvolvimento da teoria da aprendizagem social (Elkjaer, 1999). Inspirada em uma visão interacionista e pragmática, esta corrente tem como fundamento um olhar não dualista sobre a realidade, embasada nos conceitos de interação, experiência e reflexão, propostos por Dewey (1933), e pelos conceitos de mundos/arenas sociais, elaborados por Strauss (1993).

Nesta perspectiva, indivíduos vivem em um coletivo de situações nas quais interagem com outras pessoas e objetos que estão presentes como condições ambientais (Dewey, 1938). A interação (ou transação) representa aspecto transversal da experiência, envolvendo cognição e conhecimento, "o mesmo significado que a experiência, incluindo ainda a emoção, a estética e a ética, além do conhecimento" (Elkjaer, 2013, p. 92). 0 mundo externo é caracterizado como uma representação simbólica, criada e recriada junto com o mundo interno através da interação (Strauss, 1993).

A experiência é concebida como única e realizada em função das interações humanas com as condições ambientais (Dewey, 1934), englobando função projetiva e antecipatória que conecta as ações realizadas no presente com as expectativas sobre o futuro (Mische, 2009). A experiência pode apresentar uma qualidade imediata, relativa ao sentimento vivenciado pelo sujeito, e uma qualidade mediata, caracterizada pela condição de influenciar as experiências posteriores e representando aspecto longitudinal da experiência (Dewey, 1938).

A interação e a continuidade da experiência e da interação se configuram como princípios inseparáveis e intrinsecamente conectados (Dewey, 1933). A interação é permanentemente continuada e a experiência é integral, e sua interrupção, motivada por aspectos contextuais, conduz a transformação a partir da imaginação de alternativas, decisão e reorganização das ideias (Strauss, 1993). 0 mundo do 
indivíduo se expande e se contrai a partir de situações vivenciadas, gerando conhecimento e proporcionando aprendizagem, que se prolonga enquanto vida existir (Dewey, 1938). Cada indivíduo é elemento integrante e determinante da experiência, proporcionando-lhe ordenamento e configurandose como condição subjetiva desta, enquanto os objetos envolvidos se constituem como condições objetivas (Dewey, 1938).

A aprendizagem social é tida como um produto da combinação das habilidades e conhecimentos adquiridos pelos indivíduos e como um processo, resultante da participação em comunidades de prática (Brandi \& Elkjaer, 2011). Nesta perspectiva a aprendizagem não ocorre de modo extemporâneo e descontextualizado, visto que a realidade é representada a partir de aproximações e distanciamentos dos seres humanos e grupos em relação ao tempo e ao espaço (Elkjaer, 2004; Antonacopoulou, 2014). Especificamente, o estudo sobre o tempo possibilita o reconhecimento desse dinamismo nas relações dos indivíduos com o seu ambiente físico e social.

\subsection{A Importância da Dimensão Temporal para a Aprendizagem}

0 debate sobre a importância da dimensão temporal na aprendizagem organizacional envolve uma agenda de pesquisa mediante a qual se busca o desenvolvimento de uma perspectiva integrativa que concebe a aprendizagem organizacional situada no tempo com conexões emergentes de três mecanismos: duração, ajustamento (timing) e modalidades temporais (Berends \& Antonacopoulou, 2014). 0 tempo pode ser percebido como duração quando visto como uma ameaça, devido à obsolescência ou esquecimento organizacional, ou como uma oportunidade para aprendizagem organizacional, devido à aquisição de experiência, melhorias externas de exploração, conclusão de atividades e cumprimento de resultados de longo prazo. 0 tempo como ajustamento (timing) influencia o ritmo, oportunidades e sincronização das atividades de aprendizagem organizacional. 0 tempo percebido como modalidades temporais (ou relações entre passado, presente e futuro) é inerente e recursivo, permitindo reinterpretações de experiências, conexões com a realidade, imaginação e antecipação de visões sobre o futuro.

Os atores podem assumir simultaneamente diferentes diretrizes de tempo incorporando distintas dinâmicas nas ações humanas (Emirbayer \& Mische, 1998). Essa perspectiva rompe com o pressuposto racional e instrumental de que as ações envolvem relações de causa e consequência, assumindo a posição de que a ação é um complexo fenômeno social e interativo, realizado ao longo do tempo. A natureza temporal da experiência é, nesse sentido, baseada no caráter social da emergência, configurada como um processo intersubjetivo no qual os atores desenvolvem suas capacidades como deliberativas diante de situações de emergência. Neste sentido, a dimensão temporal pode ser concebida como:

um processo temporalmente embutido de engajamento social, informado pelo passado (em seu aspecto habitual), mas também orientado para o futuro (como capacidade de imaginar possibilidades alternativas) e para o presente (como capacidade de contextualizar hábitos passados e projetos futuros dentro das contingências do momento) (Emirbayer \& Mische, 1998, p. 963).

A metáfora de uma tríade de cordas é usada por Emirbayer e Mische (1998) para representar a agência humana a partir da dimensão temporal em suas três diretrizes (ou etapas sucessivas de ação): passado, futuro e presente. Assim, as pessoas vivem no presente, interpretando o passado e moldando o futuro a partir de uma atitude deliberada sobre isso. Ao longo do tempo ocorre um pensamento consciente que conecta memória, percepção e antecipação em um sentido consistente do tempo (Flaherty \& Fine, 2001).

A orientação para o futuro está relacionada ao alcance da projetividade temporal, envolvendo aspectos como improvisação, criatividade e previsão na prática de esquemas de ação. A dimensão projetiva envolve o desenvolvimento de metas, planos, objetivos e propósitos, e não apenas para resolução de problemas. A dimensão prático-avaliativa do tempo refere-se ao atendimento das demandas e contingências presentes, como o questionamento de processos existentes, as deliberações e decisões representam a estrutura interna deste tempo. A orientação pretérita está relacionada à ação iterativa, caracterizada por rotinas, hábitos, disposições e padrões de ação (Emirbayer \& Mische, 1998). Deste modo, passa a compor uma trajetória, envolvendo "(1) o curso de qualquer fenômeno experimentado à medida que evolui ao longo do tempo (...) e (2) as ações e interações que contribuem para sua evolução" (Strauss, 1993, p. 53).

Compreendendo a dimensão temporal na perspectiva de continuidade, a aprendizagem tem sua origem na: "(1) avaliação dos atuais cursos de ação; (2) exploração de futuros cursos de ação; e (3) 
reinterpretação do passado cursos de ação" (Hernes \& Irgens, 2013, p. 253). A renovação do conhecimento depende da rearticulação do significado das ações passadas diante de uma situação atual e da capacidade de antecipar o futuro.

A avaliação do desempenho possibilita aprendizagem nas organizações a partir do acesso e compartilhamento de práticas organizacionais (Hernes \& Irgens, 2013). Reconhecendo esse dinamismo para o processo de avaliação de resultados, a reflexão sobre esse processo envolve a construção da aprendizagem individual e coletiva para as ações subsequentes a serem tomadas pelos indivíduos nas organizações.

A discussão sobre estratégia nas organizações enquanto produto oriundo de previsão incorpora as preocupações atuais e a trajetória vivenciada (Kaplan \& Orlikowski, 2013). As práticas adotadas a partir da definição das estratégias contribuem para a inércia ou para a mudança organizacional. Trabalhos temporais ocorrem mediante o uso de processos de negociação e resolução de tensões sobre o transcorrer temporal de modo a balancear percepções e expectativas dos atores, como mecanismos inerentes para tornar as estratégias coerentes, plausíveis e aceitáveis.

No que diz respeito especificamente ao setor público, modelos de gestão implantados enfatizam a importância de avaliar os resultados, bem como a participação de diferentes atores nesse processo. Isso inclui tanto a competição entre as agências de prestação de serviços públicos, como a cooperação entre os diferentes interessados, visando alcançar os propósitos formulados. A complexidade inerente é a oportunidade de aprofundar o debate sobre a aprendizagem e o reconhecimento da influência temporal para atingir esses objetivos.

\subsection{A Aprendizagem de Praticantes da Estratégia no Setor Público}

Uma forma de compreender o contexto estudado é direcionar o foco de pesquisa sobre como as práticas ocorrem. A prática pode ser vista como um fenômeno, uma perspectiva e como uma filosofia. Enquanto fenômeno envolve o compromisso que os praticantes fazem, suas atividades e experiências diretas, a maneira como exercem seu labor. Enquanto perspectiva destaca-se a necessidade de observar a atividade cotidiana recorrente, a forma como a prática possibilita a construção da realidade. De outro modo, o olhar filosófico requer o entendimento de sua concepção enquanto componente da realidade, sob o ponto de vista ontológico (Orlikowski, 2010).

0 estudo das práticas se propõe a explicar como praticantes recorrem, interpretam e desafiam a estratégia organizacional vigente (Rouleau, 2013). 0 termo "praticante da estratégia" representa qualquer tipo de ator social engajado com a estratégia organizacional (ou governamental), incluindo executivos, gerentes médios, membros organizacionais da base da hierarquia, consultores, gurus, dentre outros (Whittington, 2006; Maciel \& Augusto, 2015). Os praticantes da estratégia não são representados apenas por gestores do topo da organização, mas por aqueles atores cujas práticas influenciam a estratégia, contribuindo para a sobrevivência organizacional e o alcance de vantagens competitivas (Jarzabkowski, Balogun, \& Seidl, 2007). Estes atores são responsáveis pela reprodução, transferência e inovação das práticas desenvolvidas pelas organizações, ao mesmo tempo em que objetivam sua estabilidade (Jarzabkowski, 2004).

Observa-se que os gestores públicos, compreendidos como praticantes da estratégia que realizam as práticas de gestão que contribuem para o alcance do desempenho organizacional no setor público, se veem diante de um desafio duplo: precisam aprender novos conceitos e soluções flexíveis, ao mesmo tempo em que percebem seu quadro de referência se esvair, questionados pelas constantes reformas realizadas no âmbito do Estado, que impactam frontalmente a identidade e os procedimentos padronizados existentes no setor. 0 advento das transformações no setor público demanda competências gerenciais e estratégicas aos gestores, requerendo o desenvolvimento de múltiplas habilidades em função do aumento da complexidade, da descontinuidade e da dinâmica com as quais tais profissionais são cotidianamente confrontados (Cunliffe \& Jun, 2005; Pollitt \& Bouckaert, 2011; Knassmüller \& Meyer, 2013; Cunha \& Tsoukas, 2015).

\section{Método}

0 desenvolvimento do estudo conduziu à opção de interpretação da realidade como socialmente construída, de modo que indivíduos e mundos são mutuamente concebidos (Clarke, 1991; Strauss, 1993). É necessário compreender a criação de conhecimento mediante a interpretação dos significados atribuídos pelos indivíduos às suas experiências. Optou-se pela realização de um estudo de caso 
qualitativo (Stake, 1995; Patton, 2002), com adoção da abordagem da grounded theory (Charmaz, 2014), possibilidade salientada por Merriam e Tisdell (2016).

A ênfase da teoria fundamentada (grounded theory) reside em tentar explicar as razões da diversidade e variedade de comportamentos ao longo do tempo e em relação a determinado fenômeno (Merriam \& Tisdell, 2016). Neste diapasão, a interpretação da realidade observável emerge de um processo baseado em interações sucessivas entre a coleta e análise de dados, partindo de comparações, codificações e categorizações dos fenômenos estudados, propiciados por comportamentos, ações e palavras extraídas dos atores pesquisados (Charmaz, 2014).

A abordagem da teoria fundamentada tem como foco o processo de geração de teoria a partir de conteúdos particulares (Patton, 2002; Merriam \& Tisdell, 2016), visando compreender significados e ações (e como as pessoas os constroem), pressupondo a existência de realidades múltiplas e emergentes, e expondo a verdade como algo provisório e a vida social como um processo. As teorias originadas através da grounded theory apresentam caráter empírico, baseadas em dados representativos da realidade, buscando explicar as razões da diversidade e variedade de comportamentos ao longo do tempo e em relação a determinado fenômeno (Corbin \& Strauss, 2008; Charmaz, 2014; Merriam \& Tisdell, 2016).

Inicialmente foram formulados como conceitos sensibilizantes, que representam as concepções preliminares e os interesses que orientam os pesquisadores na realização de questionamentos sobre os tópicos a serem estudados (Charmaz, 2014), os termos aprendizagem, reflexão, condições contextuais, tempo, propósito e resultado. Os conceitos sensibilizantes serviram como norteadores para a realização da seleção prévia da literatura, além de consulta em bases de pesquisa visando à identificação de referências internacionais com maior potencial de contribuição.

A composição do corpus de pesquisa transcorreu em duas etapas, conforme preceituam Merriam e Tisdell (2016). A primeira etapa envolveu a seleção do caso, tendo sido definido o PEP em função de ser uma política que tem seu foco voltado para a melhoria da qualidade da educação em escolas públicas de ensino fundamental e de ensino médio no Estado de Pernambuco. 0 fundamento principal do PEP é o acompanhamento dos resultados mediante o monitoramento de indicadores de resultados impacta na melhoria da gestão escolar e, por conseguinte, na melhoria da educação. 0 período em que a pesquisa foi realizada contempla a continuidade das ações desta política ao longo de três diferentes governos (entre os anos de 2011 e 2017).

A segunda etapa envolveu a seleção de indivíduos a serem entrevistados e materiais a serem utilizados ao longo da pesquisa, buscando-se compreender como a aprendizagem ocorreu mediante a implantação desta política. Optou-se por realizar a seleção preliminar de indivíduos a serem pesquisados, compondo este conjunto com 12 gerentes regionais que atuam no nível intermediário do PEP e 6 executivos do topo da organização. Foram adotados pseudônimos para que pudesse ser preservada a identidade dos sujeitos.

Esta escolha decorreu do reconhecimento de que a atuação dos gerentes regionais perpassa todos os níveis da rede estadual de Educação, mantendo contato com a alta cúpula do PEP, como também participando do cotidiano de escolas, permitindo a observância de aspectos vivenciados em distintos níveis hierárquicos relacionados ao PEP. Ademais, a opção por gerentes regionais possibilita a abrangência em todas as regiões do Estado de Pernambuco, tendo em vista que cada um representa um conjunto de escolas situadas em diferentes regiões do Estado. Também foi realizada a catalogação de um conjunto de 55 atas de reuniões do núcleo gestor e cinco relatórios anuais de gestão do PEP. Este procedimento contribuiu para a identificação dos principais eventos de aprendizagem de praticantes da estratégia, como também para a realização de comparações com os dados obtidos mediante outras técnicas de pesquisa. Além disso, foram incorporadas notas de campo relativas a observações realizadas pelos pesquisadores em quatro reuniões e em dois seminários de compartilhamento de experiências promovidos no âmbito do PEP.

Os processos de coleta e análise de dados ocorreram concomitantemente, em um processo de comparação constante entre os dados gerados mediante o relato de experiências compartilhadas e das relações entre os participantes e outras fontes de dados (Charmaz, 2014). A coleta de dados mediante entrevistas semiestruturadas ocorreu em quatro fases, que se prolongaram por 15 meses, entre fevereiro de 2016 e maio de 2017.

A primeira fase, realizada mediante entrevistas com os gerentes regionais, contribuiu para a construção dos códigos iniciais e para a redação de memorandos introdutórios. Na segunda fase foram 
realizadas entrevistas com executivos que possibilitaram o refinamento da codificação inicial mediante a realização de constantes comparações entre os dados obtidos, os incidentes observados e o arcabouço teórico adotado, visando à construção da codificação focalizada e a construção de categorias provisórias. A terceira fase envolveu entrevistas de follow-up realizadas com seis gerentes regionais e tinha como foco a caracterização dos principais eventos de aprendizagem e o desenvolvimento das propriedades das categorias. A quarta e última fase de entrevistas foi realizada com quatro participantes e enfatizou o processo de amostragem teórica e a validação de categorias. A partir da fase inicial, a escolha dos participantes em cada fase subsequente de coleta de dados ocorreu em função da qualidade e da intensidade das contribuições nas fases anteriores.

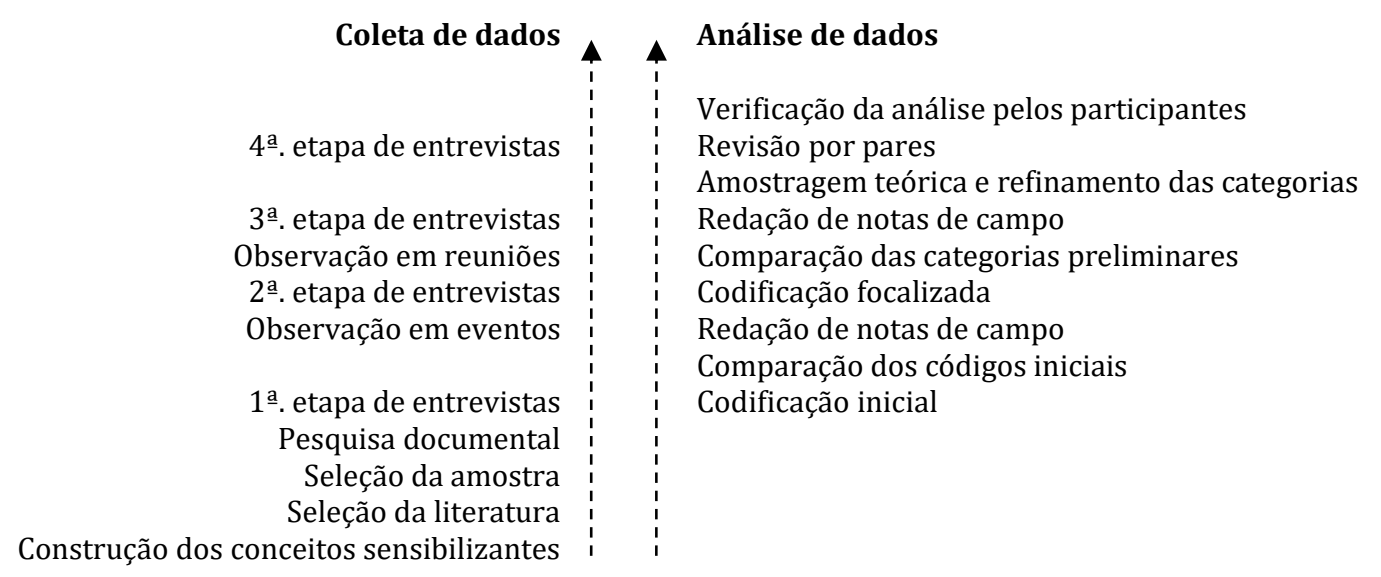

Figura 1. Procedimentos de coleta e análise de dados realizados na pesquisa.

O procedimento central do processo de análise de dados foi o pensamento comparativo sistemático sobre os dados obtidos ao longo de cada fase de coleta de dados. Através do processo de comparação constante foi realizada a codificação e a categorização dos dados, possibilitando a discussão empírica sobre a realidade observada enquanto os dados eram coletados (Charmaz, 2014). No estudo em questão, a codificação inicial foi desenvolvida mediante codificação linha a linha, possibilitando a identificação de códigos emergidos a partir das palavras expressadas neste processo, e também codificação incidente por incidente, em que são comparados os incidentes observados na fala do entrevistado. Nesta fase, foi observada a emergência de códigos in vivo, que se constituem em termos amplamente utilizados e emitidos pelos entrevistados e que representam o significado dado por estes às suas opiniões e atitudes.

Os códigos originalmente encontrados foram agrupados, o que possibilitou a descoberta de associações desconexas ou despercebidas nas etapas anteriores. Os achados foram minuciosamente analisados, visando à identificação dos códigos mais significativos e mais frequentes, de modo que estes pudessem proporcionar compreensão ao fenômeno estudado mediante a construção da codificação focalizada. 0 refinamento dos dados, códigos e categorias provisórias foi realizado através da elaboração de memorandos avançados (Charmaz, 2014). Nesta etapa foram realizadas relações entre categorias e subcategorias, em um processo de reagrupamento dos códigos gerados anteriormente, de modo a proporcionar coerência à análise. Sistematicamente foram gerados confrontos entre as proposições criadas de modo a se verificar a consistência da análise.

Este processo de refinamento de categorias com a saturação de dados é denominado amostragem teórica. Neste processo, a busca de novos dados é utilizada para preencher possíveis lacunas existentes na formulação das categorias, bem como possibilitar o desenvolvimento analítico, reforçando suas propriedades, até que estas sejam consolidadas. A amostragem teórica foi desenvolvida principalmente mediante a realização de entrevistas de follow-up, componentes da terceira e quarta etapa de investigação. Ao longo do desenvolvimento da análise dos dados as concepções provisórias foram testadas junto aos entrevistados, em um processo iterativo de coleta e análise que se encerrou com a formulação das categorias definitivas. Este processo se desenvolveu até que não fossem identificadas novas contribuições significativas oriundas dos dados obtidos.

Para ampliar a percepção de validade e confiabilidade da pesquisa foi realizada a triangulação de técnicas de coleta de dados (análise documental, entrevistas, observação), com a realização de confrontos entre as opiniões expressadas pelos entrevistados com documentos oficiais e práticas 
observadas. Outro procedimento realizado foi a revisão dos códigos por outros pesquisadores (pares). Realizou-se ainda a validação dos dados com os respondentes através de entrevistas destinadas a obtenção de confirmações ou de negações acerca do ponto de vista dos pesquisadores.

\section{Discussão de Resultados}

0 esforço de conectar o cabedal de conhecimentos apresentado na literatura com os resultados alcançados mediante a realização do estudo caracteriza o cerne da presente seção. Neste sentido, pretende-se demonstrar as contribuições originadas a partir da interpretação destes resultados empíricos relacionados à aprendizagem dos praticantes da estratégia na gestão do PEP. Estas contribuições são evidenciadas em função da constatação de que os aspectos capturados mediante relatos dos participantes, informações extraídas de documentos acessados e observações realizadas mediante a participação dos pesquisadores, serviram para reforçar, ampliar ou divergir estudos científicos anteriormente realizados.

A perspectiva adotada para a realização desta discussão está embasada no pragmatismo, especialmente em função da complexidade envolvida no entendimento do fenômeno estudado. Inicialmente o caso trazido à baila é apresentado e, logo na sequência, são expostos os resultados verificados no âmbito do contexto estudado. Então, são apresentadas as implicações oriundas do estudo no tocante à teoria, especialmente no que se refere a dimensão temporal, e à prática desenvolvida pelos praticantes da estratégia na gestão do PEP.

\subsection{0 caso Pacto pela Educação em Pernambuco}

0 advento de modelos de administração pública centrados na participação de diversos atores sociais direcionou para uma mudança na maneira de administrar o Estado. No contexto educacional brasileiro, destaca-se a adoção da gestão por resultados, caracterizado pelo uso intensivo de indicadores de desempenho associados à gestão pública.

O principal indicador de desempenho nacional adotado para avaliar a educação no Brasil é o Índice de Desenvolvimento da Educação Básica - IDEB, estabelecido em 2005. O IDEB é calculado a partir de duas dimensões: a) aprendizado, obtido a partir da média da proficiência alcançada nas disciplinas Matemática e Língua Portuguesa por estudantes participantes das avaliações externas aplicadas em diferentes etapas de ensino (fundamental e médio) e b) rendimento escolar (ou fluxo escolar) (Brasil, 2016). 0 resultado de proficiência obtido nas avaliações é multiplicado pelo indicador de rendimento escolar para obter o índice IDEB. 0 cálculo de rendimento escolar é uma relação obtida a partir da divisão do número de estudantes aprovados (ou promovidos) pelo número total de estudantes matriculados na etapa de ensino (Fundação Lemann e Merit, 2017).

O Estado de Pernambuco iniciou um esforço de recuperação do IDEM do ensino médio, considerando que na primeira divulgação dos resultados relativos à avaliação nacional, realizada no ano de 2007, a rede estadual de Educação obteve um dos últimos lugares (21ํ) na avaliação dos estudantes do ensino médio, com a maior taxa de abandono escolar no país e uma taxa de analfabetismo superior a $20 \%$ da população. Além de algumas ações isoladas, em 2011 foi elaborado o PEP, mediante a formulação e a divulgação de indicadores, bem como o estabelecimento de metas educacionais e de uma sistemática de monitoramento regular de resultados, visando a melhoria na qualidade da educação (Alessandro, et. al., 2014). 0 PEP foi regulamentado através do Decreto no 39.336/ 2013, que "estabelece o valor público como objetivo dos programas de Estado, fixa diretrizes para a Gestão por Resultados, e estabelece a execução dos pactos de resultados no âmbito do Poder Executivo Estadual" (Pernambuco, 2013).

\subsection{Interações entre os Praticantes da Estratégia na Gestão do PEP}

A introdução do PEP se configurou como um processo de aprendizagem para os gestores da educação em Pernambuco, visto que parte significativa destes profissionais se apresentava com pouco contato com as práticas de gestão por resultados no âmbito da Administração Pública. Passou-se a observar mudanças nas ações desenvolvidas pelos praticantes da estratégia atuantes no PEP, como o monitoramento de indicadores de desempenho e a participação em reuniões onde são discutidas as estratégias do Estado para a área educacional (Alessandro, Lafuente, \& Santiso, 2014).

A maneira como a educação pública era administrada em Pernambuco antes do PEP estava centrada em formas burocráticas. Os resultados mostraram a vulnerabilidade da educação estadual, 
refletida na avaliação dos gestores ao falar sobre seu trabalho. Cássia reforça essas características: "Eu acho que antes as pessoas faziam muitas coisas mecanicamente. Você tem que fazer isso. Você tem que dar esse resultado. Você tem que fazer essa ação". Observa-se que essa gestora indica um processo realizado de modo rotineiro e mecânico, sem reflexão. A gerente Virgínia confirma este pensamento: "Tivemos uma visão mais tradicional da nossa prática como gestor, trabalhávamos sozinhos. (...) Não tínhamos a prática do planejamento (...) Era algo que não existia em cotidiano".

Com a introdução do PEP houve apreensão e angústia por parte dos gestores, como relata a própria Virgínia: "O Pacto estava mexendo com a estrutura das pessoas, nos deixou sem fundamento. No começo fiquei aterrorizada, angustiada, achei que não ia dar certo (...) À medida que nos familiarizamos e compreendemos o processo, a coisa ficou mais clara e nos deu uma ideia do futuro". Apesar do desconforto inicial causado, à medida que o tempo passou, os gestores começaram a incorporar os fundamentos de resultados da administração em suas atividades.

O sentido de propósito destacado pelo gestor é algo presente na adoção da gestão por resultados no PEP. Outros aspectos favoráveis à aprendizagem, como diálogo, transparência, empoderamento de gestores e incentivos financeiros, também foram identificados. Os processos adotados, como pactuação de metas, intervenções e a comparação de resultados também contribuíram para o fortalecimento do PEP.

É possível estabelecer uma hierarquia de reuniões presenciais. As reuniões estratégicas ocorrem no núcleo gestor do pacto e contam com a participação do governador e das secretarias estaduais, além da equipe executiva da Secretaria Estadual de Educação, incluindo gerentes regionais e diretores de escolas. Cada gerente regional conduz reuniões táticas com sua equipe, com a participação de diretores de escola e técnicos de educação. Finalmente, no nível da escola, são realizadas reuniões operacionais, conduzidas pelo diretor da escola e sua equipe de gestão, além de professores e representantes dos alunos, pais e responsáveis e membros da sociedade civil. Para uma melhor compreensão do tipo de reunião no PEP, o quadro 1 é apresentado abaixo:

Quadro 1 - Tipos de reuniões do Pacto pela Educação em Pernambuco

\begin{tabular}{|c|c|c|c|}
\hline Reunião & Frequência & Participantes & Ações Realizadas \\
\hline $\begin{array}{l}\text { Monitoramento } \\
\text { (Estratégico) }\end{array}$ & Semestral & $\begin{array}{l}\text { Comitê Gestor Executivo } \\
\text { (governador, secretários de } \\
\text { Estado) e gerentes regionais. }\end{array}$ & $\begin{array}{l}\text { Apresentação e discussão dos resultados, } \\
\text { traçando estratégias e destravando processos } \\
\text { visando à melhoria de resultados. }\end{array}$ \\
\hline Pactuação & Anual & $\begin{array}{l}\text { Secretário de Educação, gerentes } \\
\text { regionais, diretores de escola. }\end{array}$ & $\begin{array}{l}\text { Exposição dos resultados obtidos no ano } \\
\text { anterior e apresentação das metas anuais } \\
\text { estabelecidas para o ano vigente. }\end{array}$ \\
\hline Tática & Bimestral & $\begin{array}{l}\text { Gerentes regionais, equipe de } \\
\text { apoio da regional e da SEPLAG, } \\
\text { diretores de escolas prioritárias. }\end{array}$ & $\begin{array}{c}\text { Apresentação e discussão dos resultados das } \\
\text { escolas prioritárias, traçando estratégias para os } \\
\text { problemas identificados, através do } \\
\text { compartilhamento de ideias e experiências. }\end{array}$ \\
\hline Operacional & Mensal & $\begin{array}{l}\text { Equipe de apoio da regional e da } \\
\text { SEPLAG, diretores de escolas } \\
\text { prioritárias operacionais e equipe, } \\
\text { estudantes. }\end{array}$ & $\begin{array}{l}\text { Apresentação e discussão dos resultados } \\
\text { obtidos pelas escolas, bem como } \\
\text { acompanhamento dos encaminhamentos } \\
\text { gerados nas reuniões táticas. }\end{array}$ \\
\hline
\end{tabular}

Fonte: elaborado pelo autor, com base em dados fornecidos pela Secretaria de Planejamento e Gestão - SEPLAG (2017).

O processo do PEP se inicia com a definição pela equipe executiva da Secretaria de Educação das metas a serem alcançadas pela rede estadual no IDEB. Essa determinação de metas, com base em indicadores de desempenho, é realizada de maneira centralizada (top-down), sem a participação direta de gerentes regionais ou diretores de escolas. As reuniões de pactuação acontecem anualmente e, como relatado por Nelci, "todos os anos os diretores das escolas estaduais assinam um acordo de pactuação, que descreve o objetivo a ser alcançado na avaliação". Essas reuniões funcionam como um gatilho para o processo de reflexão, pois a necessidade de melhores resultados configura-se como um problema a ser resolvido pelos gestores. Nas palavras de Osório:

Todos os anos a escola pactua com a Secretaria de Educação sobre as metas a serem alcançadas; então os gerentes saem daqui e os levam para suas equipes, que os entregam aos professores como um desafio; todos os anos, somos assim (apontando para baixo), precisamos chegar aqui (apontando para cima), não conseguimos e precisamos chegar aqui (repetindo o gesto); então isso é muito desafiador.

Pode-se observar que o PEP é um desafio a ser alcançado anualmente pelo gestor regional. Podese observar que existe uma atitude favorável ao desafio proposto no processo de pactuação direcionado 
aos propósitos estabelecidos. Para Nelci: "Todos querem atingir o objetivo de melhorar a qualidade, investir no aluno (...) o principal objetivo era que a escola cumprisse o que foi pactuado durante o ano; esse é o nosso desafio: fazer com que essas escolas melhorem seus indicadores".

0 monitoramento dos resultados ocorre sob dois conjuntos de indicadores. 0 primeiro consiste em indicadores de processo, envolvendo aspectos como frequência de professores, frequência de alunos, número de alunos abaixo da média, aulas planejadas versus aulas dadas, conformidade de conteúdo e participação de famílias em reuniões. 0 debate sobre esses indicadores durante o ano letivo é desenvolvido para validar as ações em andamento ou propor ações corretivas em relação ao desempenho alcançado. Uma ilustração é dada por Salete:

Então fazemos a leitura dos resultados da escola, analisando todos os indicadores, e chamando a atenção do gestor para o fato de a escola ter muitos alunos abaixo da média em português e matemática, porque a escola não cumpriu a porcentagem de alunos que levou a avaliação interna, porque os alunos não terminaram o conteúdo por falta de professores, porque os alunos perderam tanto ... Então cada indicador é questionado.

Outro conjunto de indicadores reflete o desempenho do Estado, composto pelas avaliações realizadas com os alunos e pelo abandono da população escolar. 0 principal indicador de resultado é o IDEB. 0 debate sobre esses indicadores reflete a percepção da qualidade da educação no Estado, servindo de referência com outros estados e com outros países.

\subsection{A Dimensão Temporal na Aprendizagem de Praticantes da Estratégia na gestão do PEP}

A discussão sobre a dimensão temporal na aprendizagem de praticantes da estratégia na gestão do PEP pode ser compreendida sob pontos de vista diversos, como duração, ajustamento (timing) e modalidades temporais (Berends \& Antonacopoulou, 2014). Para melhor compreensão acerca destas perspectivas, procurou-se acompanhar o fluxo de processos apresentado pelos gestores e, a partir daí, estabelecer as relações temporais para cada etapa em análise.

A primeira etapa do processo estratégico compreende o estabelecimento de propósitos e premissas organizacionais. 0 PEP está vinculado à estratégia do governo, caracterizada como objetivo. A percepção de que o sentimento de pertencer a algo maior, uma estrutura que fornece o norte temporal, é claramente percebida no discurso de Virgínia:

O pacto veio com propósito, está servindo ao seu propósito e nós estamos ajudando (...) funciona não como um plano para hoje, mas como um plano para o futuro. (...) Todos os dias trabalhamos pensando que as partes do plano vão trabalhar juntas para nos levar a um objetivo maior, temos um foco.

Ao fazer do propósito um elemento comum a todos, o olhar para o futuro como um desafio tornase o foco do gerente, sem perder a referência ao passado, concebido como importante aliado no processo de aprendizagem. 0 entendimento dos propósitos possibilita o estabelecimento de metas e a pactuação com gestores regionais e diretores de escolas. A pactuação é um acordo inicial, sendo que sua evidência mais concreta é encontrada na assinatura dos termos de pactuação realizado pelos gerentes regionais. A avaliação de Nelci sobre a pactuação indica que "é bom porque o gestor tem um objetivo acordado, sabe onde quer chegar naquele ano (...) os diretores assinam os termos de pactuação onde é descrito o objetivo a alcançar naquele ano (...) serve para dar esse alinhamento".

Após a conclusão da negociação das metas, gerentes regionais e diretores de escolas preparam planos de ação, identificando gargalos e apresentando propostas para a implantação de atividades. As reuniões táticas, além de preparar o planejamento das ações, funcionam ao longo do ano como espaços para discutir problemas, buscar soluções e compartilhar projetos de sucesso. Para Nelci "o ponto forte são as reuniões táticas, que são aqueles acompanhamentos (...) com os gestores, para que possamos refletir individualmente e cada gestor possa compartilhar um pouco da sua experiência". Essas reuniões táticas acontecem a cada dois meses, conforme o calendário escolar, facilitando a identificação precoce de problemas que possam comprometer o desempenho escolar. Esse é um aspecto importante do processo, descrito pelos gestores entrevistados como intervenções, pois a partir delas ocorre a correção de rotas incertas para atingir os objetivos.

Os resultados também podem ser vistos como um processo em andamento e, como tal, permite aos gestores confirmar a estratégia adotada ou fazer os ajustes necessários para alcançar a situação desejada. Como acrescenta Nelci, o desempenho na gestão por resultados vem de "um trabalho de ação, reflexão e intervenção (...) 0 gestor tem um instrumento que está lá, apontando onde ele precisa melhorar". Um aspecto destacado pelos entrevistados foi a comparabilidade fornecida pelo 
monitoramento de resultados. "Fazemos muitos resultados cruzados comparando o resultado de um indicador com o outro e tiramos conclusões para as escolas e algumas ações que elas precisam tomar para realmente mudar a situação", afirma Genúsia.

A troca de experiências tornou-se uma prática informal generalizada, funcionando como uma oportunidade de aprendizagem. As reuniões possibilitam um alinhamento temporal entre os diferentes atores, possibilitando a sincronização de atividades e ajustes dentro do ritmo da atividade em andamento. Recentemente foram realizados seminários de boas práticas com gerentes regionais e diretores de escolas para formalizar essas práticas e dar suporte institucional a essas iniciativas.

\subsection{Implicações para a Teoria}

O ciclo de formulação, implantação e avaliação estratégica do PEP, materializado na forma de vários encontros, possibilitou a participação e contribuição dos praticantes da estratégia no processo, contribuindo para melhoria da gestão pública. $O$ alinhamento das ações individuais com a ação organizacional ocorreu por meio do estabelecimento de propósitos. A introdução do PEP na atividade gerencial gerou, inicialmente, sentimentos de incerteza, que para Dewey (1933) representa um gatilho para o processo de aprendizagem. Posteriormente, o PEP permitiu um alinhamento, quando os gestores passaram a se concentrar na realização de finalidades, dando sentido ao trabalho.

Esse pensamento reafirma as ideias de Dewey (1933) sobre o direcionamento das ações para os propósitos. 0 praticante da estratégia interage com os outros, o que possibilita o estabelecimento de planos de ação, onde são estabelecidas as estratégias para atingir as metas e os meios para atingir os objetivos declarados (Dewey, 1938). A construção dos propósitos configura-se como um aspecto importante na condução das atividades dos gestores, conectando a ação individual à organizacional e exigindo a necessidade de aprender diante dos desafios formulados.

Os planos de ação são realizados em reuniões táticas e operacionais, criando um ambiente propício para o envolvimento dos atores. Brandi e Elkjaer (2011) apontam que o papel do indivíduo na teoria da aprendizagem social é estar engajado na criação de significado e conhecimento por meio da participação, deixando as organizações fornecerem ocasiões para permitir suas interpretações. Constatou-se no PEP que o ambiente construído foi a favor da participação, abertura ao diálogo, transparência e empoderamento dos diversos atores (Alessandro et. al., 2014).

0 alinhamento entre expectativas dos indivíduos com fins organizacionais permite a realização de interações e negociações com outros indivíduos envolvidos. A negociação inerente aos resultados é configurada como um processo duplo, onde as questões são discutidas de acordo com interesses e interações entre os atores. Clarke (1991) acredita que os mundos sociais são formados por grupos de pessoas que compartilham o compromisso com determinadas atividades para atingir seus objetivos.

Os processos de ação e interação dos indivíduos são moldados por diferentes tipos de ordens, dentre as quais a ordem temporal está presente, corroborando com o pensamento de Strauss (1993). Essa ordem temporal é identificada pelo cumprimento de questões de escalonamento, ritmo, frequência, duração e tempo das ações. É evidente que a negociação de parâmetros de desempenho, começando com um entendimento comum dos objetivos dentro das restrições temporais, é um aspecto importante da aprendizagem.

A perspectiva que associa tempo como duração é entendida como uma função da existência de um calendário para o processo educacional ao longo de cada ano. A dimensão do tempo também é observável como sucessão de eventos. As reuniões de monitoramento para discutir os indicadores de processo, realizadas nas unidades regionais, ou para discutir os indicadores de resultados representam uma sucessão de eventos ao longo do ano.

Avaliações internas e externas são pré-definidas de acordo com o cronograma da atividade. Observa-se que o tempo atua como fator limitante estabelecendo limites que às vezes não se enquadram nas necessidades e condições identificadas pelos praticantes da estratégia. Outro aspecto temporal diz respeito à percepção do resultado como componente da aprendizagem. 0 resultado pode ser entendido como um problema quando não está alinhado com o esperado, funcionando como um gatilho para um processo de reflexão.

A compreensão do tempo como continuum entre ontem, hoje e amanhã, ressalta sua importância para o processo de aprendizagem. A verificação da passagem do tempo possibilita a continuidade na realização das ações, a fim de verificar o progresso de qualquer iniciativa, monitorando os mecanismos a qualquer momento. Antecipam-se decisões para corrigir distorções no planejamento, o que é 
entendido pelos gestores regionais como um processo de intervenção. A existência de reuniões para discutir os indicadores de processo reforça o entendimento da continuidade das ações e indica a necessidade de ajustes para alcançar o desempenho esperado. Há uma reinterpretação temporal contínua das ações com o monitoramento dos resultados.

Para Kaplan e Orlikowski (2013), os gerentes realizam trabalho temporal, conectando suas interpretações do passado e do presente, com visões do futuro para construir e reconstruir suas ações. 0 trabalho de monitorar os resultados permite que o gerente analise constantemente o que foi planejado. A reinterpretação das ações realizadas e os resultados alcançados, comparados com as metas, possibilitam o ajuste de iniciativas a serem empreendidas em consonância com as finalidades estabelecidas. A realização de ajustes na implantação dos planos de ação propostos pelos gestores e diretores das escolas ao longo do ano indica que os gestores estão acessando referências temporais para realizar tarefas gerenciais e que estão aprendendo com esse processo.

Esta revisão contínua do desempenho da ação possibilita, para Hernes e Irgens (2013), o desenvolvimento da aprendizagem e dos mecanismos de compartilhamento de práticas organizacionais. É o que denominam como agência temporal, meio de reflexão direta pelo qual o ator acessa o passado, presente e futuro para manter um curso de ação. No caso do PEP observou-se que o compartilhamento de ideias / projetos (relacionados ao futuro) e de experiências / histórias (relacionadas ao passado) é uma prática informal, e se repete nas reuniões táticas e operacionais. Percebeu-se também que as ações corretivas tomadas nos processos de intervenção caracterizam a busca pela manutenção do que foi planejado, visando atingir a meta. A institucionalização do compartilhamento de ideias, práticas e experiências promovido com a realização de seminários de boas práticas de gestão reforça processos de aprendizagem no PEP.

A interpretação dos achados indica a existência de relações entre aprendizagem em diferentes níveis gerenciais e a dimensão temporal no PEP. O processo de aprendizagem vivenciado pelos gestores regionais foi discutido a partir de uma comparação com o desempenho da administração pública, utilizando o resultado como base e modelo previamente presentes. A existência de ciclos de aprendizagem é identificada, impulsionada por reuniões em níveis gerenciais de atividade. Esses ciclos são influenciados pela capacidade dos gestores de reavaliarem continuamente suas ações e seus resultados, comparando-os com os demais nos níveis estadual, nacional e internacional, provocando reflexão sobre mudanças necessárias para atingir os objetivos estabelecidos.

A elaboração desta pesquisa evidenciou a existência de lacunas a serem futuramente trabalhadas por pesquisadores visando ao desenvolvimento científico sobre aprendizagem. Espera-se que os resultados obtidos não sejam compreendidos como conclusivos, mas que despertem o interesse no aprimoramento dos debates sobre o tema explorado, configurando-se como semente para o desenvolvimento de novas pesquisas.

\subsection{Implicações para a Prática}

Os resultados alcançados na pesquisa contribuem para a construção de conhecimentos sobre aprendizagem de praticantes da estratégia no âmbito do setor público, proporcionando implicações para a atuação dos gestores no PEP. 0 desenvolvimento dos praticantes da estratégia atuantes na gestão do PEP é importante, pois visa construir e consolidar ações gerenciais exitosas.

As informações contidas no estudo possibilitam um melhor entendimento sobre como ocorre a aprendizagem de praticantes da estratégia atuantes na gestão do PEP, facultando aos candidatos a gestores a compreensão de requisitos que serão demandados para atuarem no setor público e, em especial, na política pública estudada. 0 reconhecimento da dimensão temporal enquanto aspecto que influencia a aprendizagem nas organizações é essencial para a formação de gestores públicos, mediante a construção de programas de treinamento direcionados para este público.

A pesquisa desenvolvida oportuniza aos gestores de pessoas a condição de refletirem sobre as práticas de desenvolvimento realizadas no âmbito do setor público. Os achados identificados no estudo contribuem para a elaboração de trilhas alternativas que visem à edificação de propostas que contemplem o reconhecimento do pensamento reflexivo sobre as experiências vivenciadas pelos atores ao longo do tempo como possibilidade para aprendizagem.

Suplementarmente, a realização da pesquisa proporcionou aos atores do PEP a reflexão sobre suas ações e sobre suas experiências, oportunizando questionamentos sobre a significância de suas atuações no PEP e impulsionando-os para a construção de soluções inovadoras para os problemas 
vivenciados. A concretização deste estudo provoca no poder público o desafio de ampliar os instrumentos existentes e estabelecer novas formas de incentivar a disseminação de tais experiências e das soluções oriundas da reflexão promovida no âmbito do PEP.

\section{Conclusões}

A aprendizagem de praticantes da estratégia é concebida como um grande desafio dado o contexto de transformações observado no setor público. 0 uso de ferramentas de gestão do setor privado, especialmente no que se refere ao processo de planejamento estratégico, aliado ao aumento da participação de diversos atores na proposição e implantação de políticas públicas, criou uma necessidade dos gestores e organizações públicas de desenvolver novos conhecimentos.

O PEP é uma política pública estabelecida em 2011 como o objetivo de garantir educação pública de qualidade e desenvolvimento profissional. Neste sentido, foram apresentadas evidências de aprendizagem no que diz respeito às suas partes na implantação de ações no processo de gestão baseada em resultados, permitindo identificar a influência da dimensão temporal.

No entanto, apesar das conquistas, existem lacunas na compreensão desse fenômeno em particular. Como bem ilustrado no PEP, há numerosos casos observados em todo o mundo onde a aprendizagem no setor público não foi explorada. A necessidade de um processo contínuo de reflexão sobre ações em esfera pública é clara. Para isso, é necessária uma expansão de estudos sobre como o processo de aprendizagem é construído coletivamente e como a avaliação contínua dos resultados pode influenciar a aprendizagem de participantes e organizações ao longo do tempo.

\subsection{Limitações da Pesquisa}

É indispensável reconhecer a existência de aspectos de ordem teórica, metodológica ou empírica que podem se configurar como limitantes no estudo. No tocante às técnicas de coleta de dados adotadas, especificamente quanto aos dados obtidos mediante a realização de entrevistas, as respostas podem ser distorcidas e afetadas por aspectos emocionais e/ ou por reatividade do informante durante a entrevista. É atribuído aos pesquisadores o risco de serem afetados pela percepção seletiva durante a realização das observações. Além disso, os documentos analisados podem estar incompletos ou imprecisos. Para minimizar eventuais problemas foi realizada a triangulação de técnicas, adotando-se a realização de entrevistas, observação e análise documental.

A abrangência da pesquisa foi restrita a um conjunto de praticantes da estratégia atuantes no PEP. Assim, a amplitude do estudo foi limitada aos níveis estratégico e tático de decisão no contexto da política pública investigada. Não foi possível realizar o levantamento de dados junto aos diretores de escolas, coordenadores setoriais e outros membros, pertencentes a cargos que possibilitariam caracterizá-los como praticantes da estratégia no âmbito do PEP, o que se configura como oportunidade para a realização de futuros estudos.

\subsection{Sugestões para Pesquisas Futuras}

As limitações presentes nesta pesquisa propiciaram o surgimento de novas possibilidades de pesquisa. Neste sentido, sugere-se que os futuros estudos sejam direcionados para:

1) Investigar a aprendizagem de praticantes da estratégia em outros contextos;

2) Ampliar a abrangência da presente pesquisa, entrevistando atores do nível operacional;

Os tópicos apresentados acima não se configuram como exaustivos. Ao contrário, visam apenas ao aclaramento e sinalização de novas trilhas que podem ser percorridas no intuito de ampliar o conhecimento acerca do tema aprendizagem. Espera-se, com isso, contribuir para a realização de estudos vindouros que venham a proporcionar a consolidação da temática estudada.

\section{Referências}

Alessandro, M., Lafuente, M., \& Santiso, C. (2014, April). Governing to deliver: reinventing the center of government in Latin America and the Caribbean. Monograph. Inter-American Development Bank, 224, 75-103.

Alessandro, M., Lafuente, M., \& Shostak, R. (2014, April). Leading from the center: Pernambuco's management model. Technical note. Inter-American Development Bank, 638, 1-33.

Antonacopoulou, E. (2014). The experience of learning in space and time. Prometheus, 32(1), 83-91. 
Berends, H., \& Antonacopoulou, E. (2014). Time and organizational learning: a review and agenda for future research. International Journal of Management Reviews, 16(4), 437-453.

Brandi, U., \& Elkjaer, B. (2011). Organizational learning viewed from a social learning perspective. In Easterby-Smith, M., \& Lyles, M. (eds.). Handbook of organizational learning and knowledge. (Vol. 1, Chap. 2, pp. 23-41) . Chippenham: John Wiley \& Sons.

Brasil (2016, jun.). Índice de desenvolvimento da educação básica - IDEB. Brasília: Instituto Nacional de Estudos e Pesquisas Educacionais Anísio Teixeira - INEP. Recuperado em 02 jun., 2016, de <http://portal.inep.gov.br/web/guest/ideb>. Charmaz, K. (2014).Constructing grounded theory. London: Sage.

Clarke, A. (1991). Social words/arenas theory as organizational theory. In Maines, D. (ed.), Social organization and social process: essays in honor of Anselm Strauss. New York: Aldine de Gruyter. Corbin, J., \& Strauss, A. (2008). Pesquisa qualitativa: técnicas e procedimentos para o desenvolvimento de teoria fundamentada. Porto Alegre: Artmed.

Cunha, M., \& Tsoukas, H. (2015, August). Reforming the state: understanding the vicious circles of reform. European Management Journal, 33(4), 225-229.

Cunliffe, A., \& Jun, J. (2005, March). The need for reflexivity in public administration. Administration \& Society, 37(225), 225-242.

Dewey, J. (1933). How we think: a restatement of the relation of reflective thinking to the educative process. In Boydston, J. John Dewey: the later works, 1925-1953 (Vol. 8., Chap. 1, pp. 105-352).

Carbondale: Southern Illinois University Press.

Dewey, J. (1934). Having an experience. In Dewey, J. Art as experience (Vol. 1, Chap. 3, pp. 35-57). New York: Perigee.

Dewey, J. (1938). Experience and education. In Boydston, Jo Ann. John Dewey: the later works, 19251953 (Vol. 13, Chap. 1, pp. 1-62). Carbondale: Southern Illinois University Press.

Dos-Santos, M., Brito-de-Jesus, K., Souza-Silva, J., \& Rivera-Castro, M. (2015, jul./set.). Aprendizagem organizacional e suas modalidades: desenvolvendo a habilidade interpessoal nos programas trainees. Faces, 14(3), 94-113.

Easterby-Smith, M., \& Lyles, M. (2011). The evolving field of organizational learning and knowledge management. In Easterby-Smith, M., \& Lyles, M. Handbook of organizational learning and knowledge (Vol. 1, Chap. 1, pp. 1-20). Chippenham: John Wiley \& Sons.

Elkjaer, B. (1999). In search of a social learning theory. In Easterby-Smith, M.. Burgoyne, J., \& Araújo, L. (eds.). Organizational learning and the learning organization: developments in theory and practice (Vol. 1, Chap. 5, pp. 75-91). London: Sage.

Elkjaer, B. (2004). Organizational learning: the 'Third Way'. Management Learning, 35(4), 419-434. Elkjaer, B. (2013). Pragmatismo: uma teoria da aprendizagem para o futuro. In ILLERIS, K. Teorias contemporâneas da aprendizagem (Vol. 1, Cap. 5, pp. 91-108). Porto Alegre: Penso.

Emirbayer, M., \& Mische, A. (1998). What is agency? American Journal of Sociology, 103(4), 962-1023. Flaherty, M., \& Fine, G. (2001). Present, past and future: conjugating George Herbert Mead's perspective on time. Time and Society, 10(2-3), 147-161.

Fundação Lemann e Merit (2017). Portal QEdu.org. Recuperado em 30 abr., 2017, de $<$ http://www.qedu.org.br/brasil/ideb>.

Hernes, T., \& Irgens, E. (2013). Keeping things mindfully on track: organizational learning under continuity. Management Learning, 44(3), 253-266.

Hoon, C. (2007, June). Commitees as strategic practice: the role of strategic conversation in a public administration. Human Relations, 60(6), 921-952.

Jarzabkowski, P. (2004). Strategy as practice: recursiveness, adaptation, and practices-in-use. Organization Studies, 25(4), 529-560.

Jarzabkowski, P., Balogun, J., \& Seidl, D. (2007, January). Strategizing: the challenges of a practice perspective. Human Relations, 60(1), 5-27.

Kaplan, S., \& Orlikowski, W. (2013). Temporal Work in Strategy Making. Organization Science, 24(4), 965-995.

Knassmüller, M., \& Meyer, R. (2013, March). What kind of reflection do we need in public management? Teaching Public Administration, 31(1), 81-95.

Maciel, C., \& Augusto, P. (2015, Nov./Dez.). Praticantes da estratégia e as bases praxeológicas da indústria do management. Revista de Administração de Empresas, 55(6), 660-672. 
Merriam, S., \& Tisdell, E. (2016). Qualitative research: a guide to design and implementation. San Francisco: Jossey-Bass.

Mische, A. (2009, September). Projects and possibilities: researching futures in action. Sociological Forum, 24(3), 694-704.

Osborne, S. (2006). The New Public Governance? Public Management Review, 8(3), 377-387.

Orlikowski, W. (2010). Practice in research: phenomenon, perspective and philosophy. In: Golsorkhi, D., Rouleau, L., Seidl, D., \& Vaara, E. Cambridge handbook of strategy as practice. (Vol. 1, Chap. 1, pp. 2333). Cambridge: Cambridge University.

Patton, M. (2002). Qualitative research and evaluation methods. Thousand Oaks: Sage.

Pernambuco. Assembléia Legislativa. Decreto no. 39.336, de 25 de abril de 2013 (2013). Estabelece o valor público como objetivo dos programas de Estado, fixa diretrizes para a gestão por resultados, e estabelece a execução dos pactos de resultados no âmbito do poder executivo estadual. Diário Oficial do Estado de Pernambuco. Recife. Recuperado em 26 abr., 2013, de $<$ http://legis.alepe.pe.gov.br/arquivoTexto.aspx?tiponorma=6\&numero=39336\&complemento= $0 \&$ ano $=2013 \&$ tipo $>$

Pernambuco. Secretaria de Educação e Esportes de Pernambuco - SEE: Balanço da Educação 2016 (2016). Recife. Recuperado em 20 mar., 2017, de <http://www.educacao.pe.gov.br/portal/upload/galeria/12289/BALAN\%C3\%870 \%20DA\%20EDUCA\%C3\%87\%C3\%830\%202016(1).pdf>.

Pollitt, C. (2007). The New Public Management: an overview of its current status. Administratie SI Management Public, 8(1), 110-115.

Pollitt, C., \& Bouckaert, G. (2011). Public management reform: a comparative analysis - a new public management, governance, and the neo-weberian state. New York: Oxford University.

Rouleau, L. (2013). Strategy-as-practice research at a crossroads.M@n@gement, 16(5), 547-565.

Sfard, A. (1998, March). On two metaphors for learning and the dangers of choosing just one.

Educational Researcher, 27(2), 4-13.

Shakespeare, W. (2018). Sonnet 123: no time thou shalt not boast that I do change. Recuperado em 30 mar., 2018, de <https://www.poetryfoundation.org/poems/56222/sonnet-123-no-time-thou-shaltnot-boast-that-i-do-change>.

Stake, R. (1995). The Art of Case Studies Research. Thousand Oaks: Sage.

Strauss, A. (1993). Continual Permutations of Action. Nova Iorque: Aldine de Gruyter.

Whittington, R. (2006). Completing the practice turn in strategy research. Organization Studies, 27(5), 613-634. 